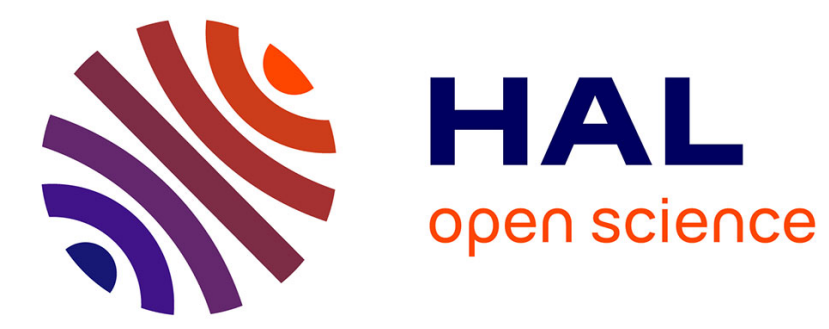

\title{
The Barkas effect or Z31-contribution to stopping of swift charged particles
}

\author{
G. Maynard, C. Deutsch
}

\section{To cite this version:}

G. Maynard, C. Deutsch. The Barkas effect or Z31-contribution to stopping of swift charged particles. Journal de Physique Lettres, 1982, 43 (7), pp.223-227. 10.1051/jphyslet:01982004307022300 jpa00232035

\section{HAL Id: jpa-00232035 https://hal.science/jpa-00232035}

Submitted on 1 Jan 1982

HAL is a multi-disciplinary open access archive for the deposit and dissemination of scientific research documents, whether they are published or not. The documents may come from teaching and research institutions in France or abroad, or from public or private research centers.
L'archive ouverte pluridisciplinaire HAL, est destinée au dépôt et à la diffusion de documents scientifiques de niveau recherche, publiés ou non, émanant des établissements d'enseignement et de recherche français ou étrangers, des laboratoires publics ou privés. 
Classification

Physics Abstracts

52.25

\title{
The Barkas effect or $Z_{1}^{3}$-contribution to stopping of swift charged particles
}

\author{
G. Maynard and C. Deutsch \\ Laboratoire de Physique des Plasmas (*), Bât. 212, Université Paris XI, 91405 Orsay, France
}

(Reçu le ler décembre 1981, accepté le 15 février 1982)

\begin{abstract}
Résumé. - La contribution des collisions lointaines au terme en $Z_{1}^{3}$ du pouvoir d'arrêt dû aux électrons liés, est mise sous une forme compacte et analytique. Elle est pondérée sur la structure atomique de quelques éléments lourds à l'aide du potentiel effectif proposé par Green-Sellin-Zachor. L'intérêt pour la fusion inertielle par ions lourds est souligné.
\end{abstract}

\begin{abstract}
The distant collision part of the $Z_{1}^{3}$-contribution to the stopping of nonrelativistic ions by bound electrons is written in a compact analytical form. Its magnitude is considered for a few species through a structure-dependent electron-ion effective interaction (GSZ potential). Relevance to ion-driven inertial fusion is stressed.
\end{abstract}

The growing attractiveness of ion beams as an ICF (Inertial Confinement Fusion) driver stems largely from the perception that the beam-target energy coupling will be "classical ». That is, while laser light coupling has been found to involve many non-linear effects [1] and it has been necessary to strive for " enhanced " deposition levels for electron beams [2] it is anticipated that ion beam energy coupling will only involve well understood " linear " physical processes at the energy deposition levels required to drive efficient pellet implosions. Moreover, with ions one has the possibility of tailoring both the ionic species and the accelerator voltage to simultaneously optimize the beam generation and target coupling efficiencies. In order to design the required ICF targets, it is necessary [3] to have an energy deposition model that is capable of accurately predicting the ion range and energy deposition profile as a function of material composition, density, temperature, and the degree of material ionization for a variety of different ionic species and beam energies. A major constraint to be placed on such an energy deposition model is that it must retain enough generality and flexibility to handle a wide variety of ion and material combinations while retaining sufficient computational efficiency to be used as a subprogram in the large hydrodynamic or magnetohydrodynamic codes used for studying target physics, and beamchannel transport [4].

To reach these goals, we proceed here to a reinvestigation of the $Z_{1}^{3}$-contribution to the stopping power of bound electrons in a target with atoms of charge $Z . Z_{1}$ denotes the charge of the projectile ion with a velocity $V_{1}$.

The $Z_{1}^{3}$-close collision term $J_{c}$ is of quantitative significance at relativistic energies only [5].

(*) Associé au C.N.R.S. 
So, we may safely neglect it for ions with a few $\mathrm{MeV} /$ nucleon, the energy range of interest for heavy ion driven fusion.

The energy-loss formula can then be written as :

$$
\frac{\mathrm{d} E}{\mathrm{~d} x}=2 Z_{1}^{2} I_{\mathrm{d}}+Z_{1}^{3} J_{\mathrm{d}}
$$

where the customary lowest-energy loss (Bohr-Bethe-Bloch) is expressed as twice a long-distance contribution. The idea of $Z_{1}^{3}$ (and higher) distant contributions is straightforwardly accounted for through successive Born corrections.

According to this approach $[5,6], J_{\mathrm{d}}$ is specified with a minimum impact parameter

$$
a=\left(\frac{\hbar}{2 m \omega_{0}}\right)^{1 / 2}
$$

and a dimensionless parameter $\zeta=\left(\frac{\hbar \omega_{0}}{2 m V^{2}}\right)^{1 / 2}$ pertaining to a classical harmonic oscillator with energy $\hbar \omega_{0}=1.123 \bar{I}_{0} \cdot \bar{I}_{0}$ being a characteristic ionization energy, and $m$ denotes the electron mass.

The $Z_{1}^{3}$ stopping power correction thus reads $[5,6]$

$$
Z_{1}^{3} J_{\mathrm{d}}=\frac{4 \pi n Z}{m^{2} V_{1}^{5}}\left(Z_{1} e^{2}\right)^{3} \int_{0}^{\infty} \mathrm{d} \omega g(\omega) I\left(\frac{\omega a_{\omega}}{V_{1}}\right)
$$

in terms of a differential oscillator strength $g(\omega)$ such that $\int_{0}^{\infty} g(\omega) \mathrm{d} \omega=1$, and a target atom density $n$.

The dynamics of the projectile-bound electron system is entirely contained within

$$
\begin{aligned}
& I(\xi) \equiv \int_{\xi}^{\infty} \frac{\mathrm{d} u}{u^{2}}\left(-K_{1}(u) \int_{-\infty}^{\infty} \mathrm{d} v \frac{\cos u v}{\left(1+v^{2}\right)^{5 / 2}}\left[\left(v^{2}-2\right) F_{1}(u, v)-3 v F_{2}(u, v)\right]+\right. \\
& \left.\quad+K_{0}(u) \int_{-\infty}^{\infty} \mathrm{d} v \frac{\sin u v}{\left(1+v^{2}\right)^{5 / 2}}\left[3 v F_{1}(u, v)-\left(1-2 v^{2}\right) F_{2}(u, v)\right]\right)
\end{aligned}
$$

The functions $F_{1}$ and $F_{2}$ are defined by

$$
\begin{aligned}
& F_{1}(u, v) \equiv \int_{-\infty}^{v} \mathrm{~d} y \frac{\sin [u(v-y)]}{\left(1+y^{2}\right)^{3 / 2}} \\
& F_{2}(u, v) \equiv \int_{-\infty}^{v} \mathrm{~d} y \frac{y \sin [u(v-y)]}{\left(1+y^{2}\right)^{3 / 2}}
\end{aligned}
$$

$K_{v}$ is the modified Bessel function of the second kind of order $v . a_{\omega}$ denotes a minimum impact parameter. The purpose of this letter is twofold :

- to give $I(\xi)$ a much more compact expression,

- to evaluate numerically the relative importance of $J_{\mathrm{d}}$ through a more flexible bound electron distribution $\rho(r)$. 
Here, we want to make use of an interesting analogy between the $Z_{1}^{3}$-term and the quadrupole contribution to the electron broadening of neutral lines in Stark broadening theory [7].

Quadratures very similar to

$$
M_{\mu, \nu}\left(z, z^{\prime}\right)=\int_{-\infty}^{+\infty} \mathrm{d} x \frac{\mathrm{e}^{i z x}}{\left(1+x^{2}\right)^{\mu / 2}} \int_{-\infty}^{x} \mathrm{~d} y \frac{\mathrm{e}^{-i z^{\prime} y}}{\left(1+y^{2}\right)^{v / 2}}
$$

have already been reduced to a sum of products of modified Bessel function [7].

Actually, all the quadratures contributing to $I(\xi)$ may be derived from $M_{\mu, v}\left(z, z^{\prime}\right)$ and its derivatives with respect to the arguments.

This allows one, after lengthy manipulations, to reduce equation (3) to the much simpler expression

$$
\frac{I(\xi)}{2 \pi}=\xi K_{1}(\xi)\left[K_{0}(\xi) I_{0}(\xi)-K_{1}(\xi) I_{1}(\xi)\right]+\int_{\xi}^{\infty} \mathrm{d} u K_{1}(2 u) K_{1}(u) I_{1}(u),
$$

with $I_{v}$, modified Bessel function of the 1st kind.

- For $\xi \ll 1$, we extend a previous limit with

$$
I(\xi) \simeq-\frac{3 \pi}{2} \log \xi-2.417-2 \pi \xi^{2}\left[(\log \xi)^{2}+1.14 \log \xi-0.33\right]
$$

- For large arguments, we get a decay

$$
I(\xi) \simeq \frac{1}{4}\left(\frac{\pi}{\xi}\right)^{3 / 2} \mathrm{e}^{-2 \xi}, \quad \xi \rightarrow \infty
$$

differing slightly from the Ashley et al. [6] expression.

Recalling that $g(\omega)$ is related to the electron distribution $\rho(r)$ in a target atom (ion) by

$$
\begin{aligned}
& Z g(\omega)=\int \mathrm{d}^{3} r \rho(r) \delta\left\{\omega_{0}(r)-\omega\right\}, \\
& \omega_{0}(r)=\sqrt{\frac{8 \pi \rho(r) e^{2}}{m}} \equiv \sqrt{2} \omega_{\mathrm{p}}
\end{aligned}
$$

we propose to compute equation (2) in the best condition through a Thomas-Fermi like GSZ expression $[8,9]$.

$$
4 \pi r^{2} \rho(r)=\frac{N x}{d}\left(\frac{H \mathrm{e}^{x}}{(H T+1)^{2}}\right)\left(-1+\frac{2 H \mathrm{e}^{x}}{1+H T}\right)
$$

where $T=\mathrm{e}^{x}-1$ and $x=r / d . N$ is the number of bound electrons in a given atom (ion). The two parameters $\left(a_{0}=\right.$ Bohr radius) $[8,9]$

$$
\begin{gathered}
0.5 \leqslant \frac{d}{a_{0}} \leqslant 1.3 \\
H=1.05 \times d \times N^{0.4}
\end{gathered}
$$


Table I. $-J_{\mathrm{d}}$ and $F(V)$ data.

1) $Z=10$

$$
\begin{aligned}
V & =0.5 \\
& =1 \\
& =1.5 \\
& =9 \\
& =9.5 \\
& =10
\end{aligned}
$$

2)

$$
z=20
$$$$
V=0.5
$$$$
=1
$$$$
=1.5
$$$$
=9
$$$$
=9.5
$$$$
=10
$$$$
J_{d}=0.22196
$$$$
=0.29387
$$$$
=0.27711
$$$$
=0.05799
$$$$
=0.05412
$$$$
=0.05064
$$

( Ne)

$$
\begin{aligned}
F(V) & =0.327 \\
& =0.371 \\
& =0.366 \\
& =0.179 \\
& =0.173 \\
& =0.167
\end{aligned}
$$

(Ca)

$$
\begin{aligned}
J_{\mathbf{d}} & =0.21793 \\
& =0.25206 \\
& =0.23594 \\
& =0.058472 \\
& =0.054863 \\
& =0.051600
\end{aligned}
$$

$$
\begin{aligned}
F(V) & =0.215 \\
& =0.257 \\
& =0.267 \\
& =0.170 \\
& =0.166 \\
& =0.162
\end{aligned}
$$

.3)

$$
Z=80
$$

$d=0.620$

(Hg)

$$
\begin{aligned}
V & =0.5 \\
& =1 \\
& =1.5 \\
& =4 \\
& =4.5 \\
& =5
\end{aligned}
$$$$
J_{d}=0.20626
$$$$
=0.24476
$$$$
=0.23434
$$$$
=0.14005
$$$$
=0.12717
$$$$
=0.11601
$$

$$
\begin{aligned}
F(V) & =0.205 \\
& =0.254 \\
& =0.271 \\
& =0.251 \\
& =0.244 \\
& =0.236
\end{aligned}
$$

4)

$$
Z=90
$$

$d=0.980 \quad(T h)$

$$
\begin{aligned}
V & =0.5 \\
& =1 \\
& =1.5 \\
& =4 \\
& =4.5 \\
& =5
\end{aligned}
$$

$$
\begin{aligned}
F(Y) & =0.178 \\
& =0.231 \\
& =0.252 \\
& =0.246 \\
& =0.240 \\
& =0.234
\end{aligned}
$$

specify equation (8) for a given target atom. Upon introducing a dimensionless ratio $V=V_{1} / \sqrt{Z} V_{0}$ with $V_{0}=e^{2} / \hbar$. The $Z_{1}^{2}$-term becomes

$$
I_{\mathrm{d}}=\frac{C}{\beta^{2}} \int_{0}^{\infty} \mathrm{d}^{3} r \rho(r) \xi K_{1}(\xi) K_{0}(\xi),
$$


with

$$
\xi=\sqrt{\frac{\hbar \omega_{0}(r)}{m r^{2}}}, \quad C=\frac{4 \pi N_{0} e^{4}}{m C^{2}}=0.307 \mathrm{MeV} \cdot \mathrm{cm}^{2} \cdot \mathrm{g}^{-1} .
$$

The relative magnitude of the $Z_{1}^{3}$ (Barkas)-term is measured finally

$$
F(V)=\sqrt{Z} V^{2} \frac{J_{\mathrm{d}}}{2 I_{\mathrm{d}}}
$$

displayed in table I for four typical atoms and small and large $V$ values respectively. $F(V)$ is typically 15 up to 30 per cent of the $Z_{1}^{2}$-term. $J_{\mathrm{d}}$ is obviously a non-negligible quantity. It was found convenient to put equation (2) under the form :

$$
J_{\mathrm{d}}=\frac{C}{\beta^{2}} \frac{2}{\sqrt{Z}} \cdot \frac{1}{V} \cdot \int \mathrm{d}^{2} r \rho(r) I(\xi) \xi^{2} .
$$

In contradiction to the Lenz-Jensen expression which does not discriminate the atomic structure, GSZ is more selective because it is built upon the experimental data for the lowest bound states.

A detailed comparison of our results with the experimental data [10] will be given elsewhere.

\section{References}

[1] KIDDER, R., in Laser interactions and related plasma phenomena, Eds. H. J. Schwartz and H. Hora (Plenum Press, New York) 1981, p. 303.

[2] Informal Workshop on the Penetration of Charged Particles in Matter Under Extreme Conditions, New York University, January, 1980 (unpublished), Ed. S. Stern. See also Deutsch, C., Bull. Soc. Fr. Phys. 40 (1981) 1.

[3] Mehlhorn, T. A., Sand 80-0038, Sandia Laboratories, Albuquerque, 1980 (unpublished).

[4] Nardi, E., Peleg, E. and Zinamon, Z., Phys. Fluids 21 (1978) 574.

[5] Jackson, J. D. et McCarthy, R. L., Phys. Rev. B 6 (1972) 4131.

[6] Ashley, J. C., Ritchie, R. H. and Brandt, W., Phys. Rev. B 5 (1972) 2393, also :

Hill, K. W., Merzbacher, E., Phys. Rev. A 9 (1974) 156.

[7] Deutsch, C., Klarsfeld, S., Phys. Rev. A 7 (1973) 2081, see also : MAYNARD, G., Thèse 3e cycle, Orsay, January 1982.

[8] Green, A. E. S., Sellin, D. L., ZaChor, A. S., Phys. Rev. 184 (1969) 11.

[9] Darewyck, J. W., Green, A. E. S., Gellin, D. L., Phys. Rev. A 3 (1971) 502.

[10] LindHARD, J., Nucl. Instrum. Methods 132 (1976) 1.

Andersen, H. H., BaK, J. F., KnUdsen, H., Nielsen, B. R., Phys. Rev. A 16 (1977) 1929. 